plishment and the safest of the three operations. But into the somewhatdifficult subject as to which of these threeoperations it is best to adopt whenever litholapaxy is found inpracticable in male children and boys I do not for the present iatend to enter, as my main object in this paper is to show that litholapaxy can deal successfully with the great majority of calculi which the surgeon meets with in male children and boys. The information compiled in the accompanying table proves the truth of my contention, and when I add that out of eighty-six male children and boys who were admitted in to the Indore Hospital during the past three years suffering from stone in the bladder I treated seventy-nine by litholapaxy, it will be seen that my opinion is based on solid ground.

But when I advocate litholapaxy as being the best operation, in my opinion, for the great majority of cases of atone occurring in male children and boys, I do so with a very important reservation-viz., that no one should attempt to perform it in boys until he has first gained some practical experience of it in adult males. The surgeon who meets with cases of stone only at rare intervals during his career will be acting more wisely if he adheres to lateral lithotomy or supra-pubic cystotomy. It is his misfortune, and not his fault, that he has not been afforded many opportunities of gaining a practical familiarity with the use of the lithotrite. But, on the other hand, he must not flatter himself that because he has performed a successful lateral lithotomy or a supra-pubic cystotomy for a stone weighing thirty grains on a boy of ten years of age, into whose urethra a No. 8 lithotrite would have readily passed, that that boy has been especially lucky in coming under his care. For he may rest assured that the boy would have been luckier still had he been entrusted in the first instance to the care of one skilled in performing litholapaxy.

I perceive that there is a tendency in some quarters in England to eliminate the word "litholapaxy" from the nomenclature of surgical operations; or perhaps it would be more correct to say that there is a tendency to make the word "lithotrity" include "litholapaxy." The words "lithotrity" and "litholapaxy" are neither of them perfectly happy in designating the operation first practised by Bigelow for ridding the bladder of a stone. To put it figuratively, "lithotrity" is so absorbed in crushing the stone that it omits all mention of evacuating the débris, whilst "litholapaxy" is so taken up with evacuating the débris that it ignores the crushing. I must, however, confess that I have a special liking for the word "litholapaxy," because, in the first place, wheneverit is used everybody interested in the surgery of stone in the bladder knows perfectly well what the word implies; and in the second place, I like it because its continued use in surgical nomenclature will have the effect of inseparably connecting Bigelow's name with a new era in the surgery of stone in the bladder.

Perhaps "lithotrity (Bigelow)" might with advantage be substituted for "litholapaxy," and, as Mr. Buckston Browne proposes, the word "litholapaxy" could then be exclusively employed in designating that operation by which calculi are extracted from the bladder through evacuating tubes without using the lithotrite. But lithotrity as first practised by Bigelow-i.e., lithotrity coupled with total evacuation of all débris at one operation, should not be confounded with the obsolete lithotrity of many crushings, without evacuation of débris, which preceded the year 1878 . I remark that there is a tendency to confound these two very different operations, and to make them do duty one for the other when statistics and other questions bearing on the surgery of stone in the bladder come under discussion. For instance, Sir Henry Thompson in a footnote to a letter which appeared in THE LANCET of Feb. 15th, 1890, page 372, tells us that there is nothing new in performing lithotrity in children, and that the only thing novel about it is that it is now applied to large stones in this class of patients. Everybody who knows any thing about the history of the surgery of stone in the bladder knows perfectly well that years and years ago lithotrity without evacuation of the débris of stone at the time of operation was practised with disastrous results. But lithotrity by Bigelow's method, or litholapaxy, when applied to male children and boys, is new, or comparatively new; and, what is still better, is an eminently successful operation in practised hands, and was first performed at the Indore Hospital, Central India.

St. James's-square, S.W.

\section{FIVE CASES OF LIGHTNING STROKE} OCCURRING SIMULTANEOUSLY.

BY PERCY POPE, M.R.C.S.,

JUNIOR ASSIS'TANT MEDICAL OFFICLR, STATE CRIMINAL ASYLUM.

ON Saturday, Aug. 2nl, whilst a cricket match was being played on the club ground of the Aldershot Division at Aldershot, five men (privates in the regiments stationed there), who were onlookers, were struck by lightning and severely injured-one fatally. Being present at the time, and having assisted in rendering immediate aid to the unfor. tunate men, my olsservations may possibly be of interest. I will preface my remarks by mentioning that the storm had shown but few symptoms of its close proximity. Heavy clouds had been observed approaching from the north, and but one or perhaps two flashes of distant lightning observed. No rain liad fallen, and the match was in actual progress when the fatality occurred. On the north side of the cround is a row of small trees, chiefly beeches and poplars, and under these trees were congregated many of the men who, stationed at Aldershot, were watching the match. The unlooked-for flash of lightning, with simultaneous thunder, which I can best describe by comparing it to the bursting of a shell, was immediately followed by cries for help by the unfortunate men under one particular tree which had been struck, and a piece of bark about three feet from the ground detached. The size of the piece was about two feet long by six inches wide. Surgeon Trask, who was also playing in the match, and myself at once hurried to the spot. The flash was immediately followed by heavy rain. For the sake of convenience I will describe the cases under numbers, No. 1 being the most severely injured and No. 5 the least injured. The men were carried out from under the tree and immediately exa. mined. No. 1 was found to be dead; the respiration and pulse had ceased. Artificial respiration was persisted in for some minutes without avail. The face was florid, and the heat of the face and body appeared to the hand to be above the normal. (The man had been for some time watching the match, and was therefore not heated by exercise) The conjunctivis were congested; pupils dilated; eyes open. The hands were not clenched, and all the muscles ap. peared flaccid. There were no marks of injury to the head or face. This man had been sitting on the ground with his back to the tree, and the piece of bark mentioned above was detached just above his head. His com. rades who lifted him described his head as being stuck to the tree. There were no marks (as I mentioned) on the head, and no hair on the tree, and I attribute their description of the man's state to the weight of a dead man's head falling backwards. No. 2 was quite unconscions. The respiration had ceased ; the pulse was still perceptible. There were marks of burning (resembling ecchymoses) on the left side of the face, neck, and upper part of the left side of the chest, which appeared to branch off from the greatest part of injury on the neck and shoulders, forming the arborescent lines described in text-books; but they did not appear to me to resemble in any way the "photograph of the tree." The hair on the left side of the head was burnt and singed. In this case artificial respiration was rewarded after some minutes by a gradual return to consciousness. Brandy was administered. As soon as possible the patient was covered with blankets and removed to the pavilion, and later to the Cambridge Hospital, Aldershot. In this case also the conjunctivie were congested (the pupils I did not see till some minutes after the shock). As vitality returned the patient complained of severe pain in the legs. (This was the remark of all those badly injured who recovered. They were not paralysed.) He was restless, semi-conscious, pulse feeble and somewhat quick. The condition reminded me more of the state described as reaction with excitement which is seen in concussion of the brain than in anything else. The patient vomited. During this condition he was removed to the hospital. Nos. 3,4 , and 5 were able to be assisted at once to the pavilion; they were placed in the recumbent position and stimulants administered. Conscious. ness returned some few minutes after being strnck. Before being removed to hospital they were able to answer the following questions. They none of them remembered being struck, or calling out immediately afterwards. They felt nothing until they returned to consciousness. No. 3 
complained of severe pain in his head, his left arm and both legs, especially the legs. The lower limbs were not para. lysed; the pains in no way resembled "pins and needles," but severe sharp continuous pains down the whole length of the thighs and legs at back. No. 4 complained of pain in the left arm and leg similar to No. 3; no pain in head. No. 5 complained of pain in both thighs and legs from the hips downwards, especially at back; no pain in the head. Nos. 3, 4, and 5 did not vomit. The survivors all stated that they felt quite warm, and did not feel cold at any time.

For some minutes after the occurrence the atmosphere smelt most strongly of fire, the fumes being slightly sulphurous, resembling more the smell that is generated by the electric sparks given off from a very large dynamo. Several others near the spot were knocked down by the electric current, but did not receive injuries neces. sitating medical assistance. Most of the players in the field experienced a "shock"-some mildly, others more severe.

P.S.-Since writing the above I have courteously been informed by the surgeon in charge (Cambridge Hospital) that the men all progressed favourably and returned to duty a few days afterwards.

Broadmoor.

\section{Clinital altotes:}

\section{MEDICAL, SURGICAL, OBSTETRICAL, AND THERAPEUTICAL.}

\section{\& CASE OF RUPTURED GRAAFIAN FOLLICLE, PRODUCING FATAL PERITONITIS}

By Joseph Wiglesworth, M.D. LoNd., M.R.C.P.,

SUPERINTENDENT, RAIYHILL ASYLUM ; LECTLRER ON MENTIL DISEASES, UNYVRSITY COLLEGE, LIVERPOOL

THE rarity with which fatal results occur as a sequel to rupture of a Graatian follicle renders the following case one worthy of being placed on record.

Harriet $A-$, aged twenty-four, was admitted into Rainhill Asylum on Oct. 18th, 1889. She had suffered from epilepsy since eleven years of age, and during the last year or two had had associated with the fit attacks of mental excitement, which had proved temporary ; during the intervals between the attacks she was fairly bright and rational. She had menstruated regularly since the age of feurteen, and her fits were usually worse at these periods. She had not, however, menstruated since her admission into the asylum. Nothing of note occurred until Jan. 7th, 1890, when she complained of dyspeptic symptoms, foul tongue, and bad taste in the mouth. On the following day, not appearing so well, she was put to bed, and an examination revealed pain and tenderness in the hypogastric region. On the 9 th the pain and tenderness had spread all over the abdomen ; the temperature rose to $1034^{\circ}$ in the morning, and $104.6^{\circ}$ in the evening, and the pulse was quick and wiry. It was clear, indeed, that the peritonitis had already become general. On the 10th the temperature fell to $101 \cdot 2^{\circ}$ in the morning and $1004^{\circ}$ in the evening; but the abdominal pain and tenderness continued in spite of the free administration of opium. On the 11 th a free menstrual discharge set in, and the patient appeared better. The improvement was maintained on the following day (the $12 \mathrm{th}$ ), but on the 13th the menstrual flow stopped rather suddenly, and collapse set in. The abdomen was now much distended and tympanitic. The collapse gradually deepened, and the patient died on the evening of the 14th.

At the necropsy, which was made on Jan. 16th, very acute peritonitis was disclosed, the intestines being glued together with recent lymph, and the pelvic cavity containing almost pure creamy pus. The right ovary exhibited on its upper surface a ruptured cyst the size of a large marble; the cyst arose from a broad base, and the orifice was likewise broad with somewhat jagged margins; a small, partly decolourised clot was attached to the floor. The cyst wall was thin, and a microscopical examination by Dr. Thelwell Thomas showed no epithelial lining. It was clearly simply a ruptured Graafian follicle. Adjoining the large cyst was a small one, the size of a pea, with a similar pro- truding little clot. The remainder of the ovary was healthy. The left ovary and the nterus were also quite healthy. There was no cause whatever discoverable for the peritonitis beyond the lesion just described. The thoracic organs were normal. Theliverand kidneys exhibited cloudy swelling of the epithelium. The uterus and ovaries were exhibited at a meeting of the Liverpool Medical Institution on Feb. 13th, 1890. liverpool.

\section{BONE GRAFTING BY DECALCIFIED BONE CHIPS.} By R. W. Murray, F.R.C.S.

I READ with much interest in THE IAANCE'T of Sept. 20th the report of Mr. Miller's successful case of bone grafting with decalcified bone chips, and feel sure that this method, as recominended by Professor Senn, is a great advance in the treatment of bone cavities. During the last two months I have on two occasions been successfal in transplanting decalcified bone chips into bone cavities, resulting from the removal of tubercular material. The first case was that of a girl aged twelve years, who was suffering from chronic tubercular disease of the carpus, bones of the forearm and elbow-joint, necessitating amputation above the elbow-joint. The lower end of the humerus was found to be so extensively diseased that the bone had to be divided one inch and a half above the condyles. The medullary cavity at the point of section was filled with unhealthy looking, gelatinous material, and the interior of the bone was scraped for a distance of two inches before healthy marrow was reached, a mere shell of bone remaining. This cavity I filled with decalcified bone chips well dusted with iodoform. The wound healed but slowly (as I had to amputate through old sinuses), but the result has been very encouraging, a firm but somewhat bulbous stump resulting, due to excess of bone formation.

The second case was that of a boy aged six years, who had old-standing disease of the tarsus, with a sinus over the inner aspect of the first metatarsal bone. I freely enlarged the sinus, gouged away the greater part of the first metatarsal bone, and probably the internal and middle cuneiform bones; the cavity resulting was then filled with decalcified chips, and the skin united over it, with the exception of an opening for a drainage-tube. A few chips in the neighbourhood of the drainage-tube subsequently came away in the form of a gelatinous aseptic slough, but by far the greater number of the grafts held, and the small sinus still remaining is granulating rapidly.

What the ultimate result will be in the second case I am not prepared to say, but so far it is at least encouraging. My reason for somewhat prematurely recording these results is to assist in giving prominence to a mode of treatment that in suitable cases will, I feel convinced, be found satisfactory.

Liverpool.

\section{SUCCESSFUL OPERATION FOR IMPERFORATE ANUS.}

By Robert Sanderson, M.B. Oxon.

Mrs. B-, a primipara aged twenty-three, was delivered naturally of a female child at full time on May $17 \mathrm{th}$, 1889, at 12.30 A.M. Presentation vertex, first cranial. Father and mother both healthy. On examining the child immediately after birth, I noted that the anus was imper. forate, the usual site of it being indicated by a faint longitudinal depression or dimple. The following morning, with the consent of the parents, I operated. On pressing the abdomen, which was not specially distended, a bead of meconium presented at the vaginal orifice, and a probe revealed a minute opening high up in the vagina, and apparently in the posterior cul-de-sac, communicating with the bowel. A silver director suitably bent was pushed into the bowel and cut down upon through the anal dimple above mentioned, and the edges of the opening into the bowel thus made were with considerable difficulty gradually drawn down and stitched with four silk sutures to the edges of the external skin. I was indebted to Mr. A. Nicholson for valuable assistance during the operation. No anæs thetic was used. The lowest part of the bowel was quite three-quarters of an inch from the external skin. So soon as the wound had 